\title{
Nanotechnology approaches to addressing HER2-positive breast cancer
}

\author{
Bryan E. White ${ }^{1 *}$, Molly K. White ${ }^{2}$, Het Adhvaryu' ${ }^{1}$ Issam Makhoul ${ }^{3}$, Zeid A. Nima², Alexandru S. Biris ${ }^{2}$ \\ and Nawab Ali ${ }^{1}$
}

*Correspondence: bewhite@ualr.edu

1 Department of Biology,

College of Arts, Letters

and Sciences, University

of Arkansas at Little Rock,

Little Rock, AR, USA

Full list of author information

is available at the end of the

article

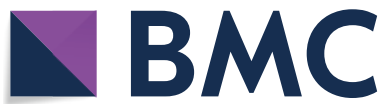

(C) The Author(s) 2020. This article is licensed under a Creative Commons Attribution 4.0 International License, which permits use, sharing, adaptation, distribution and reproduction in any medium or format, as long as you give appropriate credit to the original author(s) and the source, provide a link to the Creative Commons licence, and indicate if changes were made. The images or other third party material in this article are included in the article's Creative Commons licence, unless indicated otherwise in a credit line to the material. If material is not included in the article's Creative Commons licence and your intended use is not permitted by statutory regulation or exceeds the permitted use, you will need to obtain permission directly from the copyright holder. To view a copy of this licence, visit http://creativecommons.org/ licenses/by/4.0/. The Creative Commons Public Domain Dedication waiver (http://creativecommons.org/publicdomain/zero/1.0/) applies to the data made available in this article, unless otherwise stated in a credit line to the data. 
Table 1 FDA-approved targeting nanodrugs for HER2-positive breast cancer

\begin{tabular}{|c|c|c|}
\hline Targeting drug specific to HER2 & Mechanism of action & Reference \\
\hline Trastuzumab (Herceptin) & $\begin{array}{l}\text { Monoclonal antibody that binds to } \\
\text { the extracellular domain (ECD) of } \\
\text { the HER2/neu receptor }\end{array}$ & Targeted therapy (2019) \\
\hline Pertuzumab (Perjeta) & $\begin{array}{l}\text { Inhibits dimerization of HER2 recep- } \\
\text { tors by binding to special epitope } \\
\text { of the extracellular domain (ECD) }\end{array}$ & $\begin{array}{l}\text { PERJETA and HER2 + breast cancer } \\
\text { (2019) }\end{array}$ \\
\hline $\begin{array}{l}\text { Ado-trastuzumab emtansine } \\
\text { (Kadcyla or TDM-1) }\end{array}$ & $\begin{array}{l}\text { Targets HER2 receptors with trastu- } \\
\text { zumab and delivers the inhibitor } \\
\text { emtancine to arrest and kill cancer } \\
\text { cells }\end{array}$ & Chemocare.com (2019) \\
\hline Lapatinib & $\begin{array}{l}\text { Receptor tyrosine kinase inhibitor in } \\
\text { the ICD }\end{array}$ & Targeted therapy (2019) \\
\hline Neritinib & $\begin{array}{l}\text { Receptor tyrosine kinase inhibitor in } \\
\text { the ICD }\end{array}$ & $\begin{array}{l}\text { U.S. National Library of Medicine } \\
\text { (2019) }\end{array}$ \\
\hline Bevacizumab & $\begin{array}{l}\text { VEGF inhibitor; reduces the cancers } \\
\text { blood supply }\end{array}$ & Targeted therapy, 2019 \\
\hline Fam-trastuzumab-deruxtecan & $\begin{array}{l}\text { Humanized lgG1 monoclonal anti- } \\
\text { body, which has the same amino } \\
\text { acid sequence as trastuzumab (and } \\
\text { targets HER2. The deruxtecan com- } \\
\text { ponent is a topoisomerase inhibitor }\end{array}$ & Fam-Trastuzumab Deruxtecan (2020) \\
\hline Tucatinib & $\begin{array}{l}\text { Selectively binds to and inhibits the } \\
\text { phosphorylation of ErbB-2, which } \\
\text { may prevent the activation of } \\
\text { ErbB-2 signal transduction path- } \\
\text { ways, resulting in growth inhibition } \\
\text { and death of ErbB-2-expressing } \\
\text { tumor cells }\end{array}$ & Tucatinib (2020) \\
\hline
\end{tabular}

quality of life for patients and their families and imposes a major economic burden on the American health system. As a result, improved early diagnostic methods and novel therapies are desperately needed. The human epidermal growth factor receptor (HER2/ neu) is a growth-promoting protein that is overexpressed on the outer cellular membrane of cancer cells. Breast cancer that has an above normal level of HER2 protein is referred to as HER2-positive breast cancer.

Over-expression of the HER2 protein affects about 1 in 5 women with breast cancer (BREASTCANCER.ORG 2020). This type of cancer generally grows and spreads more rapidly than the other types of breast cancers. Current therapeutic treatment options generally include surgery, radiation followed by chemotherapy in a combined approach. Such approaches while reducing cancer progression, cause excessive damage to noncancerous cells due to inherent cytotoxic side effects of such treatments. Thus, there is an urgent need to reduce cytotoxicity in cancer treatment strategies. Nanotechnology offers hope to achieve such goals. In recent decades, enormous efforts have been made to develop nanomaterials with unique properties and characteristics. Some of these properties are exploited to develop tools for diagnosis and treatment of cancers including breast cancers. A number of nanoparticles are being developed to target and deliver potent cancer drugs primarily to the affected cells, thus minimizing toxic side effects. This area of research has evolved so rapidly that there are now several targeting drugs specific to HER2-positive breast cancer approved by the FDA. These include trastuzumab (Herceptin), pertuzumab (Perjeta), ado-trastuzumab emtansine (Kadcyla, 


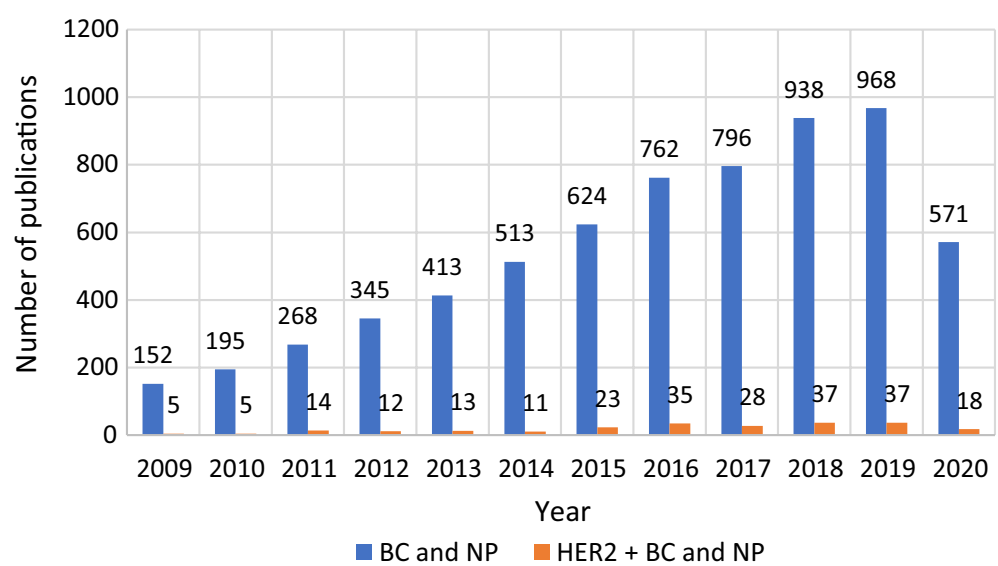

Fig. 1 Comparison of the number of breast cancer and nanoparticle (BC and NP in blue) and HER2-positive breast cancer and nanoparticle (HER2+ BC and NP in orange) related publications by year from 2009 to 2020 . The data were taken from PubMed (https://pubmed.ncbi.nlm.nih.gov/) on August 20, 2020 and is based on a keyword search using the keywords: "Breast cancer and nanoparticles", and "HER2-positive breast cancer and nanoparticles". PubMed was also searched for a comprehensive review of the literature for nanotechnology uses in HER2-positive breast cancer

or TDM-1), fam-trastuzumab-deruxtecan, lapatinib, neratinib, and tucatinib (Table 1). These drugs target the cells carrying the HER2 protein as opposed to untargeted chemotherapy that affects all dividing cells.

Side effects of targeted drugs are usually mild but occasionally can be serious. Some women develop heart damage with trastuzumab, pertuzumab, or TDM-1, which can lead to congestive heart failure. This risk of heart problems is even greater when these drugs are used with certain chemotherapies such as doxorubicin. As a result, researchers are always working to find better ways to target and address HER2-positive breast cancer (Targeted Therapy for Breast Cancer 2019).

In this review, we discuss the most common areas of research being done with HER2positive breast cancer and nanotechnology. To date, several publications exist in this area of interest, but a comprehensive review bringing all the crucial issues together has not been published. Figure 1 shows an increase in the number of nanotechnology-related breast cancer publications in the last decade addressing HER2-positive breast cancer specifically. This review focuses specifically on the key considerations for addressing HER2-positive breast cancer with nanotechnology, which include mechanisms of cellular uptake, screening and detecting, targeting and drug delivery, stem cell research, and co-delivery strategies to address drug resistance and improve treatment outcomes. Here we have organized these topics into individual sections where we provide multiple examples of the work in that area. Subsections are provided to separate each individual example under the main section. 


\section{Cellular uptake and interaction of nanoparticles with HER2-positive breast cancer}

Though nanomaterials are very useful in many important applications, research has shown that cells and tumors do not respond to every type of nanoparticle in the same way. Nanoparticle variations such as size, shape, and surface chemistry make a difference in the basic mechanisms of cellular uptake and responses as well as their usefulness in different biological applications (Panariti et al. 2012). Understanding the way specific nanoparticles interact with specific cell types is crucial for determining the usefulness of the nanoparticles as well as their effects on cells and the environment. The following review sections illustrate the nature of nanoparticle cellular uptake as it relates to HER2-positive breast cancer. Here we can see that differences in particle and cell type results in differences in the nature of the cellular uptake and localization of the nanomaterials. This section also illustrates various techniques that can be used to study the cellular uptake process of different nanomaterials in HER2-positive breast cancer cells. The following studies involve polystyrene particles in different cell types, gold nanoparticles with differing shapes, iron oxide nanomaterials, gold particles with surface modifications, dextran-spermine nanoparticles, gold nanospheres, and dendrimers. The focus of this section is strictly to understand cellular uptake in the different cancer cell models.

\section{Cellular uptake of polystyrene microparticles in different human breast cell lines}

There are multiple examples of the work being done using polystyrene particles (Sutapa Barua 2020; Martínez-Jothar 2020), but the following work highlights an example of the work being done specifically in the area of cellular uptake as it relates to HER2-positive breast cancer. Patiño et al. (2015) examined the impact of nanoparticle surface modifications on uptake efficiency for various cell types, as well as the mechanism of internalization. Polystyrene microparticles were functionalized with a fluorescently active antibody. Two types of polyethylenimine (PEI) differing in structure and molecular weight were used to coat the particles, which were then studied with two types of human breast cell lines. This study revealed that cancer cells and normal cells use different types of endocytosis pathways when interacting with different surface modifications. The tumor cell SKBR-3 showed favorable uptake to positively charged microparticles using the macropinocytosis machinery. On the other hand, the non-tumor MCF-10A cells favored a negatively charged microparticle and did not seem to favor a dominant endocytosis mechanism.

In this example, we see differences in uptake based on cell type. The mechanisms used by the two cell types differ with the same type of nanoparticle. The SKBR-3 breast cancer cells responded in a different way than the non-tumor cells MCF-10A to the same polystyrene microparticles in terms of the cellular uptake process. This study was conducted using fluorescence microscopy techniques, which is a good way to study cellular uptake and mechanisms for non-metal nanomaterials. This is a good example of how all cells do not respond the same way to the same particle type. The next example examines the cellular uptake process of gold nanoparticles with different shapes in SKBR-3 cell lines. 


\section{Cellular uptake of gold nanoparticles of different shapes in breast cancer cell lines}

Gold nanoparticles are very commonly studied in all areas of nanotechnology (Ghosh et al. 2008; Sperling et al. 2008; Dreaden 2012). In this example, we see how shape can influence cellular uptake behavior. Here, we also see how optical signatures of gold can also be used for studying cellular uptake of gold nanomaterials in breast cancer cells using UV-Vis and how this method compares to the more common Inductively Coupled Plasma Mass Spectrometry method or ICP-MS. Cho et al. (2010) introduced a method for studying the cellular uptake of gold nanoparticles with two different shapes using SKBR-3 cells. The authors showed that due to the different shapes of gold nanospheres and nanorods, their distinctive optical signatures could be exploited to measure their individual concentrations in a single sample with UV-Vis absorbance spectroscopy. Using this method, the study investigated the role of shape in the cellular uptake process. This method was compared to inductively coupled plasma mass spectrometry and proved to be useful for quantifying the uptake of nanoparticles in HER2-positive breast cancer cells. Interestingly, the results showed differences in the number of particles taken up by the cells depending on nanoparticle shape and whether they were added together or independently. Nanoparticle uptake was also dependent on the surface modification of the gold particle, e.g., polyethylene glycol (PEG) and targeting antibody anti-HER2. Not only do we see that shape makes a difference in gold particle cellular uptake, we also see here that surface coating such as PEG influences this process as well. The next example in this section looks at iron oxide nanoparticle uptake in different cell types.

\section{Cellular uptake of magnetic iron oxide nanoparticles in human breast cell lines}

Truffi et al. (2018) examined the cellular uptake process of SKBR-3 and MDA-MB-453 cell lines. Fluorescently labeled particles targeting HER2 (half chains of trastuzumab) conjugated to magnetic iron oxide nanoparticles (MNP-HC) were used to assess the mechanism of cellular uptake as well as the cellular localization. The authors showed that in the first hour, these nanoparticles accumulated at the cell membrane, but much faster in the HER2-overexpressing cell line SKBR-3. The signal was detected in the cytoplasm at 4 and $24 \mathrm{~h}$ of incubation, and at $48 \mathrm{~h}$, the signal decreased, indicating a reduced rate of cell membrane interaction. In addition, the intracellular trafficking of the iron oxide core was evaluated using transmission electron microscopy (TEM). In SKBR-3 cells, nanocrystals were detected outside the cells and attached to the cell membrane after $1 \mathrm{~h}$ of incubation. After 4 and $24 \mathrm{~h}$ of incubation, nanoparticles were seen in endosomal vesicles and later in lysosomes, suggesting an endocytosis pathway (Fig. 2).

Here, we see a few different methods for studying cellular uptake, trafficking, and localization of iron oxide nanoparticles in two different breast cell types. Iron oxide nanoparticles can easily be labeled with fluorescence and tracked using fluorescent microscopy techniques. In addition, transmission electron microscopy or TEM is an excellent way to study the internalization and localization of nanomaterials inside cells. The authors show that iron oxide particles follow the endocytic pathway in a time dependent manner for internalization in both breast cancer cell types (SKBR-3 and MDA-MB-453) using a combination of these techniques. While many works have been published in work using iron oxide (Shakil et al. 2019) the example reviewed here was based on the details found on the cellular uptake process, which many published works may not cover. 


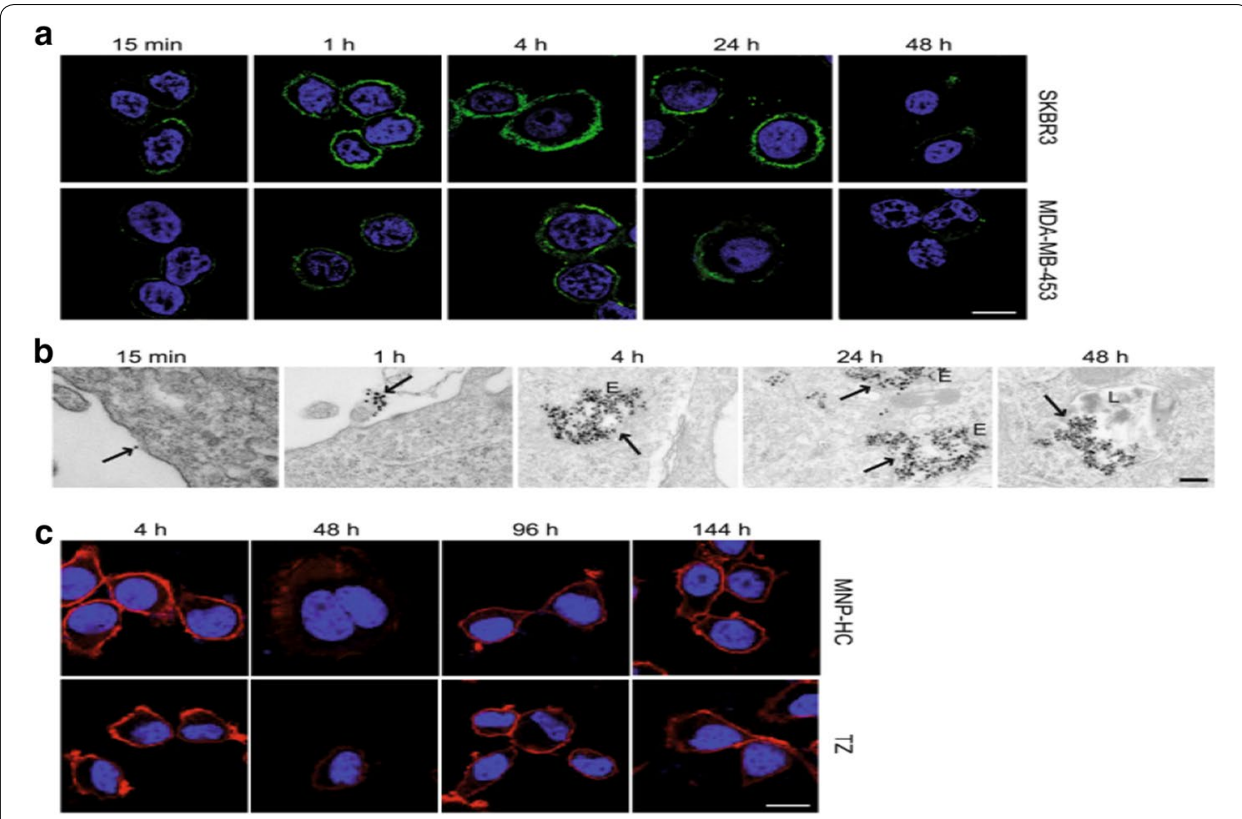

Fig. 2 Intracellular trafficking of nanoparticles. a Time course confocal microscopy of SKBR3 and MDA-MB-453 cells incubated with MNP-HC (green). Nuclei are stained with DAPI (blue). Scale bar: $10 \mu \mathrm{m}$. b TEM images of MNP-HC, pointed by arrows, in SKBR3 cells. E, endosomes; L, lysosomes. Scale bar: $200 \mathrm{~nm}$. C Confocal laser-scanning micrographs of SKBR3 cells incubated with MNP-HC or free TZ and stained for HER2 (red). Nuclei are stained with DAPI (blue). Scale bar: $10 \mu \mathrm{m}$ (Figure reproduced from Truffi et al. (2018))

The next section deals with aspects of cellular uptake of surface modified gold nanorods.

\section{Cellular uptake of conjugated gold nanorods in breast cancer cells}

Previously we saw that the shape of a gold nanoparticle has an effect on cellular uptake. In this study, we see how modifying the surface of gold nanorods for targeting plays a role in the cellular uptake process. We also see another example of how cell type influences this process as well and the use of TEM to study these processes. Kang et al. (2017) studied some aspects of cellular uptake of gold nanorods conjugated with porphyrin and trastuzumab using BT474 and SKBR-3 breast cancer cell lines. The cells were incubated with the conjugated nanorods for $48 \mathrm{~h}$ before TEM was performed. In BT474 cells, TEM showed that the conjugated gold nanorods accumulated in gaps between closely growing cells and inside the cytoplasm of the cell. Further analysis using higher magnification identified multivesicular bodies encapsulating the nanorods. Endocytic bodies with nanorods were also observed in the nucleus of the BT474 cells. In SKBR-3 cells, a few nanoparticles were observed, which led the researchers to conclude that greater uptake occurs in BT474 than SKBR-3. This was mainly due to the conjugated gold nanorods localizing on the surface of the BT474 cells, which resulted in more efficient cellular uptake.

In this example, we see how surface modification can affect the mechanics of cellular uptake. It is also important to note that the difference in cell type is very much a factor to consider as well. This is an excellent example of how small variations can influence the mechanism of cellular uptake and how important it is to investigate the cellular uptake behavior in each and every model. 
In the next example of this section, we look at the cellular uptake behavior of dextranspermine nanoparticles that have been modified for targeting.

\section{Cellular uptake of magnetic dextran-spermine nanoparticles functionalized for targeting HER2}

Cellular uptake changes with particle type, cell type, surface modification, etc. Here we see how SKBR-3 breast cancer cells respond to magnetic dextran-spermine nanoparticles. We also see another technique for studying cellular uptake, which is the Prussian blue method. Avazzadeh et al. (2017) conducted a cellular uptake assay with HER2-positive breast cancer cells using magnetic dextran-spermine nanoparticles. The nanoparticles were conjugated with anti-HER2 antibody, and the cellular uptake and targeting process was evaluated using the Prussian blue method and microscopy techniques with and without the targeting antibody. The results showed differences in cellular uptake between the SKBR-3 and fibroblast cells. A large number of antibody-conjugated nanoparticles entered the SKBR-3 cells, but none were observed in the control fibroblast cells, and no differences were seen in cellular uptake with the non-targeting nanoparticles. This study illustrates the significance of using a targeting antibody to help facilitate the cellular uptake of nanoparticles. This example highlights the nature of this specific particle type. It also shows the effect of conjugating a targeting antibody, which is discussed more in the section on targeting HER2 breast cancer.

In the next example, we describe gold particles that are spherical and look at how shape as well as size affects the cellular uptake process.

\section{Cellular uptake of HER2 targeting gold nanospheres in breast cancer cell lines}

Cruz and Kayser (2019) analyzed cellular uptake of targeting gold nanospheres using a combination of ICP-MS and TEM. Trastuzumab was conjugated to gold nanospheres, and the uptake quantification and localization in SKBR-3 cells was compared to nontrastuzumab gold nanospheres. Two sizes of nanoparticles, $20 \mathrm{~nm}$ and $50 \mathrm{~nm}$, were tested. The results found that both sizes of trastuzumab-targeting nanoparticles had enhanced cellular uptake compared to the non-targeting nanoparticles, but in both cases, cellular uptake did occur. TEM analysis showed that these particles localized in vesicular structures inside the cells (Fig. 3).

As shown in Fig. 3a, based on quantitative ICP-MS data, it is clear that there is a differential uptake of the particles based on their size. Larger particles $(50 \mathrm{~nm})$ show more uptake than smaller particles $(20 \mathrm{~nm})$ without targeting antibodies. However, both $20 \mathrm{~nm}$ and $50 \mathrm{~nm}$ particles show almost similar fold increase in particle uptake following targeted antibody conjugation as compared with the respective particles without the targeting antibody. This study shows how the size of the nanoparticles has an effect on both accumulation and localization in this particular cell type. Here we have the same cell type, same targeting mechanism, and same shape particle, but the size of the particles being used differ and have a different cellular uptake result. This study also shows how TEM and ICP-MS used together serves as a great technique for studying gold nanoparticles in breast cancer cells. 


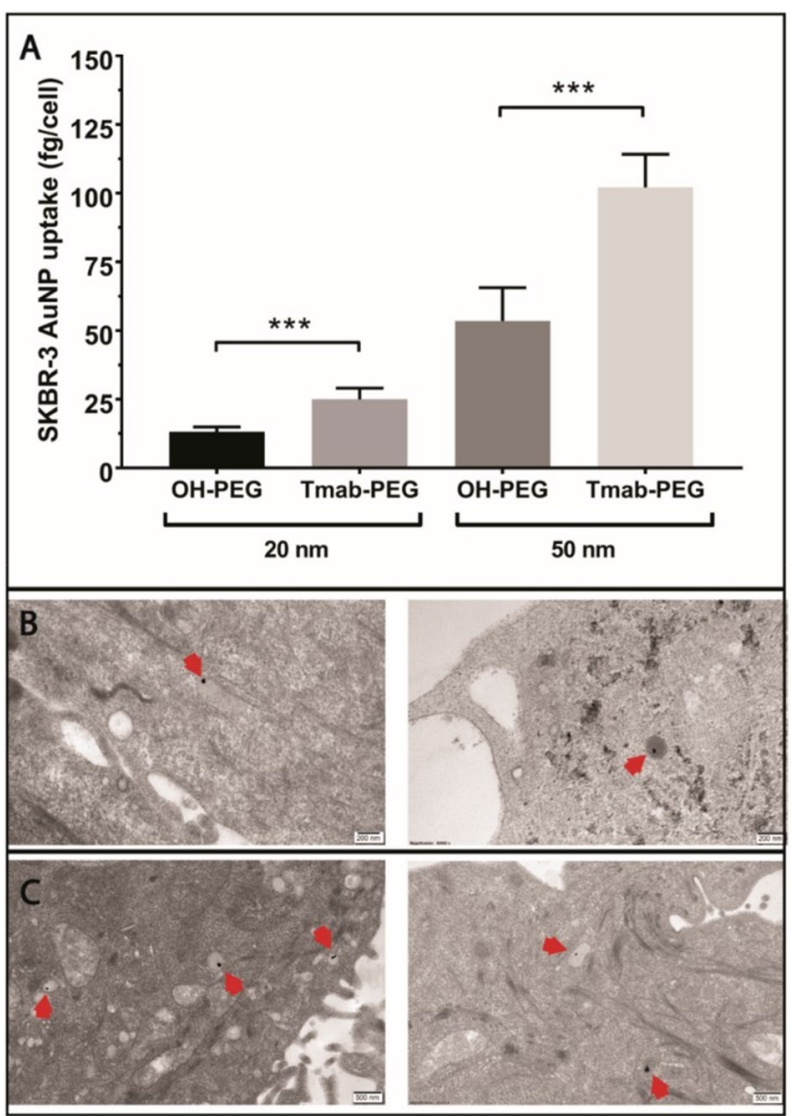

Fig. 3 Evaluation of the active targeting capacity of trastuzumab-functionalized gold nanoparticles. a ICP-MS quantification of OH-PEG-AuNP and Tmab-PEG-AuNP uptake into SKBR-3 cells after $24 \mathrm{~h}$ incubation. Uptake data are reported as means \pm SD. ${ }^{* * *} p<0.001$ (Student's $t$-test). $\mathbf{b}$ TEM micrographs of OH-PEG-AuNPs internalized into SKBR-3 cells. Scale bar $200 \mathrm{~nm}$. c TEM micrographs of Tmab-PEG-AuNPs internalized into SKBR-3 cells. Scale bar: $500 \mathrm{~nm}$ (Figure reproduced from Cruz and Kayser (2019))

Lastly, we review a nano-design involving drug-loaded dendrimers for its cellular uptake behavior.

\section{Cellular uptake of targeting and drug-loaded dendrimers in HER2-positive BC cell lines}

Dendrimeric nanoparticles have also been used to target HER2-positive breast cancer cells (Miyano 2020; Chan 2020; Rameshwer Shukla 2020) However, we found the study by Kulhari et al. (2016) significant and worth reviewing in this section due to the focus on cellular uptake. Kulhari et al. (2016) studied the cellular uptake of trastuzumab-grafted, docetaxel-loaded dendrimers conjugated to fluorescein isothiocyanate (TZ-Dend-FITC). The authors used the HER2-positive breast cancer cell line MDAMB-453 and compared it with the HER2-negative MDA-MB-231 breast cancer cell line. Combinations of targeting and non-targeting nanoparticles were used for comparison of uptake efficiency. Uptake was observed in both MDA-MB-453 (HER2-positive) and MDA-MB-231 (HER2-negative) cells. In the HER2-positive cell line, both targeting and non-targeting nanoparticles showed fluorescence after $1 \mathrm{~h}$ of incubation. The intensity 


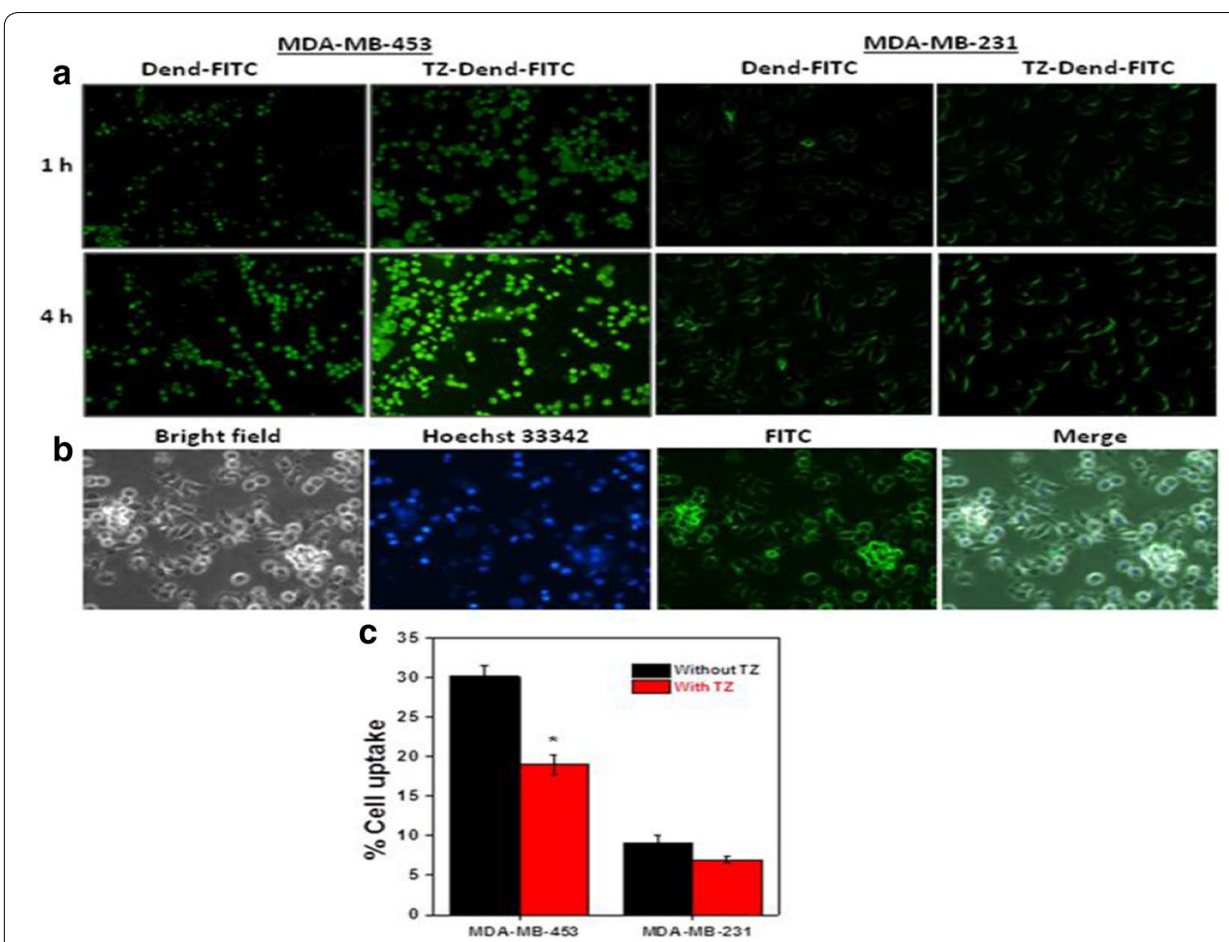

Fig. 4 a Fluorescent microscope images of MDA-MB-453 and MDA-MB-231 human breast cancer cells after $1 \mathrm{~h}$ and $4 \mathrm{~h}$ of incubation with FITC-conjugated dendrimers (Dend-FITC) and TZ-conjugated Dend-FITC (TZ-Dend-FITC); $\mathbf{b}$ fluorescent microscope images of co-cultured MDA-MB-453 and MDA-MB-231 human breast cancer cells followed by incubation with TZ-Dend-FITC; $\mathbf{c}$ quantitative uptake of TZ-Dend-FITC by MDA-MB-453 and MDA-MB-231 human breast cancer cells after $2 \mathrm{~h}$ incubation with or without TZ (20 mM). Figure reproduced from Kulhari et al. (2016) with permission

of the fluorescence was higher in the targeting nanoparticles, indicating more uptake occurred due to the targeting mechanism. The results indicated that cellular uptake of the non-targeting nanoparticles was $11.4 \%$, compared to $23.5 \%$ for the HER2-targeting nanoparticles. Results also indicated that the cellular uptake process is time dependent. After $4 \mathrm{~h}$ of incubation, cellular uptake increased for both particle types, but the targeted nanoparticles still showed higher uptake efficiency. In the non-HER2-positive cells, no difference in cellular uptake efficiency was observed between the targeted and non-targeted nanoparticles. However, in a mixed culture of the two cell types, selective targeting was observed. The mixed cell culture assay showed inhibition of uptake by the HER2negative cell line and selective uptake by the HER2-positive cell line (Fig. 4).

The studies above show that not all cell and nanoparticle combinations result in the same type of cell/particle interaction. Changes in the model-e.g., cell type, particle type, surface modification, functionalization for targeting, etc.-can result in changes in cellular uptake mechanics as cells interact with different particle sizes and surfaces differently. This suggests that with every model the cellular uptake process must be evaluated. Nanoparticle cellular uptake cannot be generally defined due to the changes seen throughout the various models. For example, we see that a cell type may employ receptor mediated endocytosis for gold nanoparticles while another cell type uses macropinocytosis for the same type of particle. In some cases, we see more quantity being taken up due to size in a certain cell type, etc. Another thing that is important to consider is the behavior of the particles themselves in 
terms of clumping and aggregation affecting the size and how cells or tumors may respond differently as a result. In this section, we have also seen that a wide range of techniques are available for studying the cellular uptake process. For gold nanoparticle analysis, we see that TEM and ICP-MS work very nicely when used in combination to study internalization, quantification, and localization of nanomaterials in breast cancer cells. For non-metal nanomaterials fluorescent labeling and TEM work well to study these processes.

In the next section, we look at some of the research being conducted in the area of screening and detecting HER2-positive breast cancer using nanotechnology.

\section{Screening and detecting HER2-positive breast cancer}

Screening for cancer leads to early diagnosis and treatments, which results in a greater chance of survival. Because early detection is of such great importance, demand has increased for advancements in cancer biomarker screening and detection. The following section is an overview of some of the designs and methods for screening and detecting HER2-positive breast cancer using nanotechnology. In this section, we review different technologies to include the use of iron oxide nanoparticles, dendrimers, and quantum dots.

\section{Detection of HER2 using iron oxide nanoparticles}

As mentioned before iron oxide is seen throughout the literature in many applications. While many applications exist, they are not all focused on screening and detecting HER2-positive breast cancer. In this example we see a successful nanotechnological design using iron oxide nanoparticles for the detection of HER2 in blood samples. Emami et al. (2014) designed a label-free immunosensor for the detection of HER2 in actual blood samples. This approach uses a differential pulse voltammetry method. Anti-HER2 antibodies were conjugated to iron oxide nanoparticles and later laid over a gold electrode surface. Under the proper conditions, this immunosensor was able to detect HER2 in specific ranges of concentrations. This sensor for detecting HER2-positive breast cancer was evaluated using patient serum samples, where it successfully quantified levels of HER2. The work here is promising as it shows that levels of HER2 can be detected accurately and easily from a patient's blood sample. In addition, iron oxide nanoparticles offer a lot of possibilities in that they can be made multifunctional for not only detection, but for drug delivery and targeting as well.

The next design reviewed in this section deals with screening for HER2-positive breast cancer using dendrimers.

\section{Screening for HER2-positive breast cancer using dendrimers}

In addition to inorganic nanomaterials such as gold and iron oxide, organic nanomaterials offer benefits as well. Here we see the use of peptides to target HER2 receptors and serve as a vehicle for screening cancer. Wang et al. (2015) used a microarray-based method to screen for HER2-positive breast cancer using two novel peptides, YLFFVFER and KLRLEWNR, that bind specifically to the HER2 receptor. This efficient peptide screening method is based on in situ sequencing of beads in a 

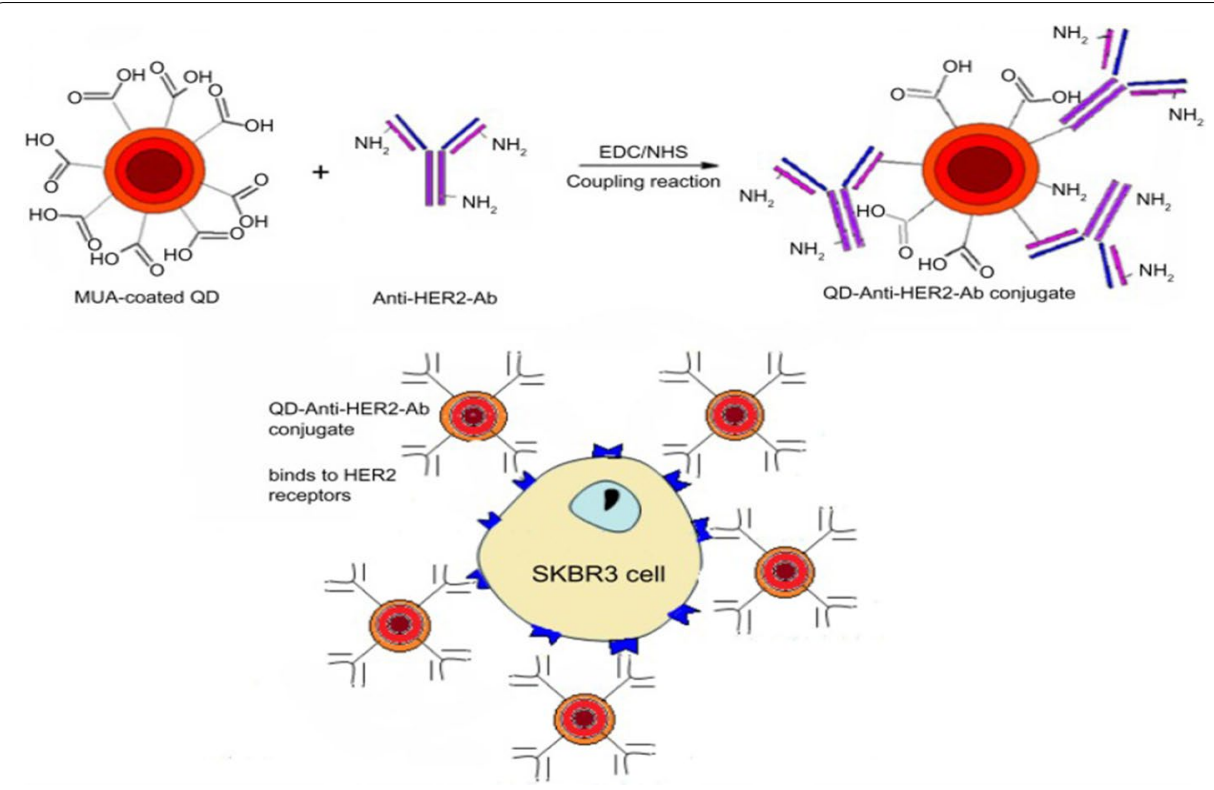

Fig. 5 Methodology of bioconjugation of mercaptoundecanoic acid-coated QDs and application for localization of HER2 receptors. Anti-HER2-AB conjugates to the QD surface through an amide linkage. The QD-Anti-HER-AB conjugate then targets and localizes to the HER2 receptors overexpressed on SK-BR-3 cells. Ab, antibody; HER2, human epidermal growth factor receptor 2; QD, quantum dot (Reprinted with permission from near-infrared quantum dots for HER2 localization and imaging of cancer cells (Rizvi et al. 2014). Originally published by Dove Medical Press Limited)

microarray system. When the peptides were conjugated to nanoparticles, they specifically accumulated in HER2-positive tumors in xenografted mice, as evidenced by in vivo imaging. This is a good example of finding alternatives to trastuzumab. The investigators of this work were able to not only come up with a microarray screening system for HER2, but the new peptides offer more options for HER2 targeting, which will be covered in a later section. The next screening technology example involves the use of quantum dots.

\section{Detection of HER2-positive breast cancer using quantum dots}

This next design illustrates how dynamic nanotechnology is in terms of functionality. Here, quantum dots are used for the detection of HER2, but we can see that the design offers multiple functions. Rizvi et al. (2014) developed a method for detecting HER2 breast cancer using quantum dots (Core/shell/shell CdTe/CdSe/ZnSe QDs). In this work, a near-infrared-emitting quantum dot bioconjugate (quantum dots conjugated with anti-HER2) was designed for the rapid localization of HER2 receptors. It can also be a tool for targeted therapy and image-guided surgery (Fig. 5). In this study, the near-infrared-emitting quantum dot antiHER2-antibody bioconjugates were successful in localizing with HER2 receptors using SKBR-3 HER2-positive breast cancer cell lines. The use of quantum dots are exciting and the authors in this work point 
out the possibilities of their multifunctionality. For example, the quantum dots being functionalized for targeting the HER2 receptor. They could also be labeled for imaging or even functionalized for anticancer drug delivery.

These are some examples of the new strategies for screening and detecting HER2 type cancer using nanosystems. This section provides an overview of some the possibilities as it relates to using nanotechnology to screen and detect HER2-positive breast cancer. As mentioned above, knowing the HER2 status of breast cancer is of extreme importance because once the HER2 status is diagnosed, then the treatment approaches can be specifically designed for that status. If the HER2 status is positive, then specifically targeting the HER2 receptor is ideal, as this type of tumor profile can be exploited for targeted drug delivery. The next section of this review dives into the all-important area of research: Targeting HER2-positive breast cancer using nanotechnology.

\section{Targeting HER2 breast cancer using nanotechnology}

Targeting cancer cells can involve the cells themselves by targeting their surface receptors or aspects of the tumor microenvironment (TME) specific to the tumor type, such as tumor $\mathrm{pH}$. To target these elements, nanomaterials can be designed and characterized with targeting moieties such as antibodies and receptor ligands. This results in a vector or vehicle that has a high affinity for binding to tumor cells, leading the nanomaterial to accumulate there. For targeting to be successful, it requires a unique identifier specific to the target itself that can be exploited. For example, the target should not be found in the normal, healthy surrounding cells so that the nanosystem does not target or interact with the normal tissue. Targeting should also facilitate the drug delivery process via endocytosis of the nanovehicle into the targeted cells (Dawidczyk et al. 2014).

The following section highlights the work being done in this area. This includes a wide range of approaches and designs for targeting HER2-positive breast cancer. It is important to note that even though these approaches were designed for therapeutic targeting, many of them are multifunctional and may also be considered for other functions, such as detection and co-delivery. In this section, we review multiple designs for targeting HER2-positive breast cancer using different nanotechnologies. These designs include targeting using iron oxide, nanobubbles, mini-nanodrugs, gold nanostars, and gold-gold sulfide.

\section{Targeting HER2-positive BC using iron oxide nanoparticles}

Choi et al. (2015) described an approach for targeting the HER2 receptors of breast cancer using a "chitosan-conjugated, pluronic-based nano-carrier", which is an ideal vehicle for different types of agents and works well for conjugating targeting ligands. In this approach, iron oxide nanoparticles were loaded inside the nano-carrier to enable MRI imaging. In addition, the nano-carrier was conjugated to Cy5.5 as a fluorophore for optical imaging. Finally, the nano-carrier was loaded with the anticancer drug doxorubicin for a therapeutic effect. Thus, making this design multifunctional in that it offers targeting, imaging, and chemotherapy. In this study, the authors confirmed active targeting in vivo and showed enhanced antitumor activity in a xenograft 
tumor model. The authors showed that the IONP/DOX loaded multifunctional nanocarrier has diagnostic capability, HER2 selectivity and therapeutic effects. This is a good example of how certain nanomaterials can be functionalized for multiple purposes. Being able to target the HER2 receptor, deliver a therapy and image the results all with one nanodrug is ideal. This design is promising in its ability to accomplish this functionality. Next, we see the use of nanobubbles to target HER2 BC.

\section{HER2 targeting nanobubble}

The novel approach described by Jiang et al. (2016) makes use of nanobubbles coupled with contrast-enhanced ultrasonography to detect vascular patterns of breast cancer. Additionally, the nanobubbles have a PEGylated phospholipid shell and are functionalized with Herceptin to specifically target HER2-positive breast cancer cells. This system relies on the principle of "theranostics", which is an approach that combines therapy and diagnostics. This nanobubble can target HER2 receptors in breast cancer and enhance contrast for diagnostic imaging, while also potentially delivering anticancer drugs.

This is another good design offering targeting as well as multifunctionality. This nanobubble targets the HER2 receptor via Herceptin. Once bound to the HER2 receptor this nano system can be used for diagnostic imaging for assessing vascular patterns and perhaps tumor growth, morphology, etc. In addition to the targeting and ability to image, we also see that this design can be functionalized for drug delivery.

\section{Targeting HER2 using a mini-nanodrug}

Ding et al. (2017) designed and tested mini-nanodrugs for HER2 targeting. In previous work conducted by this investigator using mouse models, the researchers found that trastuzumab could more effectively treat HER2-positive breast cancer when combined with a co-ligand poly(beta-L-malic acid) (PMLA) and an antisense oligonucleotide that targets the HER2-mRNA. The resultant mini-nanodrug is a HER2-mRNA-annealing morpholino antisense oligonucleotide (5'-CATGGTGCTCACTGCGGCTCCGGC $-\mathrm{NH}_{2}-3^{\prime}$ ), which targets HER2 using an anti-HER2/neu peptide or affibody (an affibody is a small protein designed to bind to a large number of target proteins with high affinity, thus, mimicking antibodies) in place of trastuzumab. The advantages of these "mininanodrugs" include replacement of antibodies, which could result in reduced cost and effort, as well as high stability, biodegradability, non-toxicity, and non-immunogenicity. The PMLA offers carboxylic groups that allow functionalization of drugs, targeting peptides, protective polyethylene glycol (PEG), peptides for destabilizing membranes, and dyes for imaging.

Targeting is of such great importance that researchers work to find stronger and better ways to facilitate the targeting process. FDA-approved trastuzumab is undoubtedly the most common way this is achieved with respect to targeting the HER2 receptor. This work shows how the targeting process can be even more effective or enhanced using this mini-nanodrug. In addition to the enhanced targeting and potential reduced cost and improved availability, this design works well for drug delivery. 


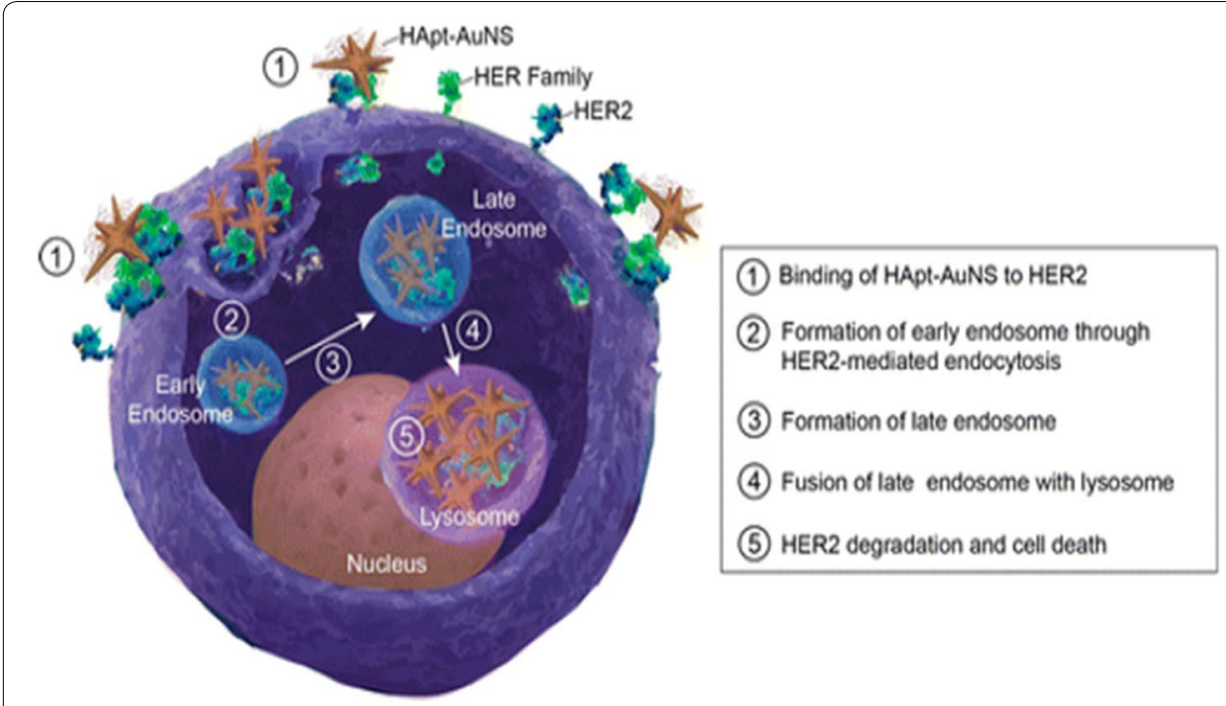

Fig. 6 Internalization process of HApt-AuNS in HER2-overexpressed cancer cells. HApt-AuNS binds to HER2 on the plasma membrane, and then the HER2-nanoconstruct complex internalizes in the cell by endocytosis. HER2-HApt-AuNS is transported from endosomes to lysosomes, where HER2 is degraded, inducing cell death (Reprinted with permission from Lee et al. (2015). Copyright 2015, American Chemical Society)

\section{Targeting HER2 using aptamer-functionalized gold nanostars}

Because targeting HER2 has proven to be a highly effective strategy, many researchers have focused on novel approaches to more effectively target the receptor. Lee et al. (2015) designed a nucleotide-based HER2 aptamer for targeted delivery via gold nanostars (AuNS) (Fig. 6). The authors chose gold nanostars because of their many advantages, which include their shape that is beneficial for detection, and their ability to be functionalized with an aptamer as a drug delivery system. This design is an anti-HER2 aptamer (HApt), which is a trimeric version made up of 42 base pairs of the HER2-specific aptamer that was previously identified. This HApt has both targeting and therapeutic capabilities. It can induce cross-linking of the HER2 receptor on the surface of the cell. It can also translocate the HER2 receptor from the plasma membrane into vesicles in the cytoplasm, which will ultimately result in degradation of HER2, thus downregulating the HER2 receptor and inducing apoptosis. The authors showed that this downregulation resulted in alteration of the cell proliferation and downstream signaling pathways.

\section{Targeting HER2 using conjugated gold-gold sulfide nanoparticles}

In 2010, Day et al. designed antibody-conjugated gold-gold sulfide nanoparticles (GGSNPs). The authors demonstrated that this combination could simultaneously provide targeting contrast agents for imaging and photothermal therapy. The gold surface is functionalized with anti-HER2 antibodies, causing the nanoparticles to target HER2 receptors of SKBR-3 cells. Photoablation was then achieved via exploitation of the optical properties of the gold surface chemistry. Upon exposure of the particles to SKBR-3 cells, a pulsed near-infrared laser was used to detect the GGS-NPs via multiphoton microscopy. The authors describe this detection method as well as the thermal damage that can occur in the cancer cells when the power output of the multiphoton is 
increased. The authors suggest that this ability to image the nanomaterials at the same time as using the photothermal agents for cancer management makes their design very attractive. This is especially important for treatments that require the integrity of the surrounding healthy tissue to be maintained.

This design using gold offers several advantages to include photoablation. Here we see targeting facilitated by the use of HER2 antibodies conjugated to gold-gold sulfide nanoparticles. This nano-design targets SKBR-3 cell lines by binding to the cell receptors, which allow for imaging and photo thermal therapy for cells killing.

Our last example for targeting is a peptide-conjugated iron oxide nanoparticle for targeting HER2-positive breast cancer.

\section{Peptide-conjugated iron oxide particles for targeting HER2}

Other nano-based strategies for targeted therapy include the use of albumin, silica gold, and carbon, to name a few. For example, the FDA-approved Abraxane is an albuminstabilized nanoparticle loaded with the chemotherapy paclitaxel (PTX). Abraxane helps to improve the effectiveness and reduce the side effects of PTX alone but is too large for optimal in vivo functionality with nanodrugs; it also has no targeting ligand. In addition to the size issue, gold, silica, carbon, and liposomes often cause toxicity and raise concerns regarding biodegradability and stability.

With respect to the anti-human epidermal growth factor receptor 2 (HER2/neu), this monoclonal antibody is commonly used for breast cancer targeting. Monoclonal antibodies have a greater advantage as targeting ligands over aptamers, small molecules, and proteins. However, the size of the monoclonal antibody alters the physical and chemical properties of the nanoparticle (NP). Mu et al. (2015) proposed an iron oxide nanoparticle conjugated with an anti-HER2/neu peptide and loaded with PTX (AHNP-IONPPTX) that seems to solve many of these problems. The design involves the anti-HER2/ neu peptide (AHNP), which is a small exocyclic peptide derived from the 185HER2/neu monoclonal antibody trastuzumab. The authors found that their design of an IONPbased, anti-HER2/neu peptide-conjugated, PTX-loaded NP is smaller than the typical albumin, liposomes, polymers and gold nanoparticles and has a uniform shape with ideal stability. This formulation showed positive in vivo and in vitro targeting capacity to human HER2/neu-positive breast cancer cells and more effectiveness in killing the cells than the larger nano formulations.

Thus, we have seen a variety of ways researchers can target HER2-positive breast cancer cells and tumors using nanotechnology. All of the examples above make use of the overexpression of the HER2 receptors in some way to exploit the cancer rather it be with the FDA-approved trastuzumab or anti-HER2 or with the more outside of the box approach of using minidrugs, peptides or aptamers. Interestingly, we see a big difference in the nanomaterial itself in these designs. The designs above include anything from iron oxide nanoparticles to the use of gold nanostars and nanobubbles. The key factor here that gives any one design an edge over the other may come down to the design's multifunctionality capabilities. In addition to targeting the cancer, what else can we hope to accomplish? Things to consider in designing this technology would certainly be the 
Table 2 Multiple designs of targeting nanodrugs for HER2-positive breast cancer

\begin{tabular}{|c|c|c|c|c|}
\hline Nanoparticle & $\begin{array}{l}\text { Targeting } \\
\text { mechanism }\end{array}$ & Cancer therapy & $\begin{array}{l}\text { Multifunction } \\
\text { capability }\end{array}$ & References \\
\hline $\begin{array}{l}\text { Pluronic-based } \\
\text { nanocarrier loaded } \\
\text { with iron oxide } \\
\text { nanoparticles }\end{array}$ & $\begin{array}{l}\text { Chitosan conjugated/ } \\
\text { HER2 targeting }\end{array}$ & Doxorubicin & $\begin{array}{l}\text { Iron oxide for MRI } \\
\text { imaging, Cy5.5 for } \\
\text { imaging, doxoru- } \\
\text { bicin for anticancer } \\
\text { therapy }\end{array}$ & Choi et al. (2015) \\
\hline $\begin{array}{l}\text { PEGylated phospho- } \\
\text { lipid nanobubble }\end{array}$ & $\begin{array}{l}\text { Herceptin targeting } \\
\text { HER2 receptors }\end{array}$ & None & $\begin{array}{l}\text { Can potentially } \\
\text { deliver anticancer } \\
\text { therapy, has ultra- } \\
\text { sonography capa- } \\
\text { bility for imaging }\end{array}$ & Jiang et al. (2016) \\
\hline $\begin{array}{l}\text { Mini-nanodrug, co- } \\
\text { ligand poly(beta-L- } \\
\text { malic acid) (PMLA) }\end{array}$ & $\begin{array}{l}\text { HER2-mRNA-anneal- } \\
\text { ing oligonucleotide }\end{array}$ & None & $\begin{array}{l}\text { Functionalization for } \\
\text { drugs, targeting } \\
\text { peptides, protective } \\
\text { PEG, peptides for } \\
\text { destabilizing mem- } \\
\text { branes and dyes for } \\
\text { imaging }\end{array}$ & Ding et al., 2017 \\
\hline $\begin{array}{l}\text { Novel humanized } \\
\text { HER2 antibody }\end{array}$ & Anti-HER2 antibody & None & $\begin{array}{l}\text { Can be used in } \\
\text { many targeting } \\
\text { applications. Has } \\
\text { advantages over } \\
\text { traditional antibod- } \\
\text { ies }\end{array}$ & Cao et al. (2015) \\
\hline $\begin{array}{l}\text { HER2 aptamer-conju- } \\
\text { gated gold nanostar }\end{array}$ & $\begin{array}{l}\text { 42-base pair HER2 } \\
\text { aptamer for target- } \\
\text { ing HER2 receptors }\end{array}$ & $\begin{array}{l}\text { Reduction of HER2 } \\
\text { receptors due to } \\
\text { lysosome degrada- } \\
\text { tion }\end{array}$ & $\begin{array}{l}\text { This HER2 aptamer } \\
\text { gold nanostar can } \\
\text { be used for detec- } \\
\text { tion while offering } \\
\text { drug delivery }\end{array}$ & Lee et al. (2015) \\
\hline $\begin{array}{l}\text { Antibody-conjugated } \\
\text { gold-gold sulfide } \\
\text { nanoparticle }\end{array}$ & $\begin{array}{l}\text { Anti-HER2 antibody } \\
\text { conjugated for } \\
\text { targeting HER2 } \\
\text { receptors }\end{array}$ & $\begin{array}{l}\text { Photothermal } \\
\text { therapy }\end{array}$ & $\begin{array}{l}\text { Simultaneously } \\
\text { provides targeting } \\
\text { contrast agents for } \\
\text { imaging and pho- } \\
\text { tothermal therapy }\end{array}$ & Day et al. (2010) \\
\hline $\begin{array}{l}\text { Iron oxide nanopar- } \\
\text { ticle }\end{array}$ & $\begin{array}{l}\text { Small exocyclic } \\
\text { peptide from the } \\
\text { 185HER2/neu } \\
\text { monoclonal anti- } \\
\text { body trastuzumab. } \\
\text { conjugated for } \\
\text { targeting HER2 } \\
\text { receptors }\end{array}$ & Paclitaxel & None & Mu et al. (2015) \\
\hline
\end{tabular}

ability to both treat the cancer or deliver a therapy and image the cancer in addition to the targeting. A summary of the targeting nanodrugs can be found in Table 2.

As mentioned before, targeting nanodrugs are ideal in that they can seek out the cancer cells while avoiding the healthy surrounding tissue. In the next section, we look at another area of extreme importance for combating HER2-positive breast cancer using nanotechnology: stem cells. When it comes to any type of cancer including HER2-positive breast cancer, there exists a lot of focus on researching stem cells. This short section reviews some of the work being done on stem cells as it relates to HER-positive breast cancer. 


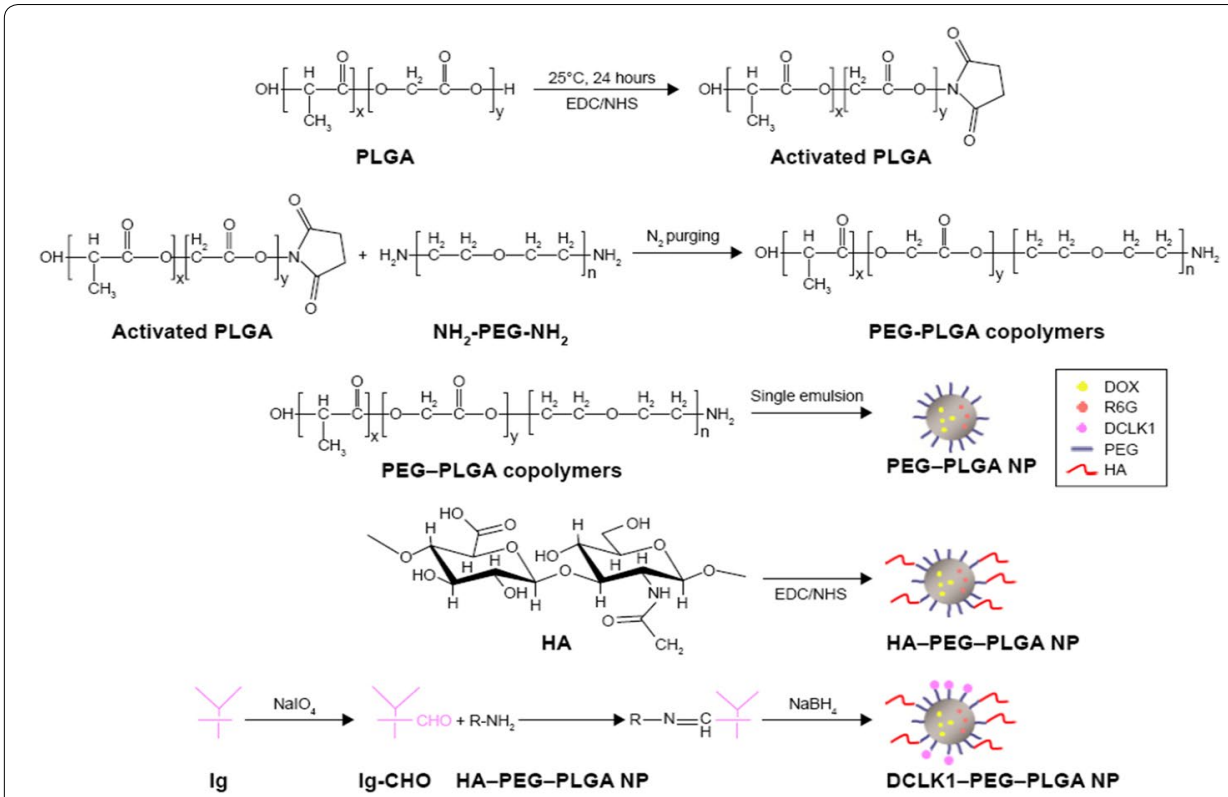

Fig. 7 A schematic illustration of the synthesis of DCLK1-HA-PEG-PLGA NP. DCLK1, doublecortin-like kinase 1; DOX, doxorubicin; EDC, 1-ethyl-3-(3-dimethylaminopropyl) carbodiimide hydrochloride; FITC, fluorescein isothiocyanate; HA, hyaluronic acid; NHS, N-hydroxysuccinimide; lg, immunoglobulin; NP, nanoparticle; PEG, poly(ethylene glycol); PLGA, poly(D,L-lactide-co-glycolide); R6G, rhodamine 6G. Reprinted with permission from A novel double-targeted nondrug delivery system for targeting cancer stem cells Qiao et al. (2016) (Originally published by Dove Medical Press Limited)

\section{Targeting stem cells to address HER2-positive breast cancer}

In the treatment of any cancer, it is important to consider targeting the cancer stem cells. Cancer stem cells are a special cell type that localize in solid cancer tumors and overexpress the CD44 receptor. Cancer stem cells are typically regarded as a determinant of cancer occurrence and can be responsible for the spreading of cancer. Cancer stem cells continue to proliferate and differentiate into cancerous cells. It is important to get rid of the cancer stem cells, the supply line, to completely remove cancer. Conventional treatments for cancer do not always kill cancer stem cells because the cells tend to be multidrug resistant, which often results in cancer recurrence. In this section, we review approaches to targeting and killing cancer stem cells with nanotechnology that are also useful for treating HER2-positive breast cancer. The designs in this section include a nondrug delivery system, a chemotherapeutic drug release system and targeting stem cells using micelles.

\section{Targeting cancer stem cells with a novel nondrug delivery system}

Qiao et al. (2016) described the development and use of a novel nondrug delivery system for targeting cancer stem cells. This design involves the conjugation of hyaluronic acid and grafting the doublecortin-like kinase 1 monoclonal antibody to the surface of nanoparticles. With this design, the cancer stem cells can be targeted. This targeting nanoparticle can seek out the CD44 receptors as well as the doublecortin-like kinase 1 (DCLK1) surface marker and distinguish between cancer stem cells and normal stem cells (Fig. 7). 
The targeting activity of this design was used in vitro as well as in vivo. The in vivo model was $4 \mathrm{~T} 1$ breast cancer stem-like cells that overexpresses the CD44 receptor and DCLK1. The authors found that the dual targeting nanoparticles were able to target cancer stem cells using this design. This has important implications in designs for targeting cancer stem cells, which can be crucial for combating HER2-positive breast cancer in terms of preventing the spread and reoccurrence of this disease. This example involves only the targeting process. Next, we look at not only targeting stem cells, but targeting and drug delivery.

\section{Targeting stem cells for chemotherapeutic drug release}

Rao et al. (2015) introduced a method for targeting cancer stem cells and releasing an engineered chemotherapeutic drug using nanoparticles. This doxorubicin-encapsulated polymeric nanoparticle is surface modified with chitosan, which specifically targets the CD44 receptors of cancer stem cells. Doxorubicin is released when the nanodrug is in an acidic environment, such as within endosomes or lysosomes. In a 3D mammary tumor spheroid model, this nanoparticle design increased the cytotoxicity of the doxorubicin by six times compared to doxorubicin alone for eliminating CD44-positive cancer stem cells. The researchers also showed that the nanosystem reduced the tumor size in an orthotopic xenograft tumor model.

Here, we see successful targeting of stem cells as well as doxorubicin delivery for the destruction of the stem cells, which is ideal. We have seen examples of this technology in a previous section where investigators target and deliver payloads to the tumor or cells themselves. Here that same technology is applied to the cancer stem cells in an attempt to attack the root of the cancer and stop it in its tracks.

Next, we look at targeting stem cells as well as stem cell detection using micelles.

\section{Targeting and detecting cancer stem cells using micelles}

Gener et al. (2015) developed a novel in vitro fluorescent cancer stem cell model for visualizing cancer stem cells in a heterogeneous population. This model was utilized for preclinical validation of a specific type of micelles loaded with paclitaxel. The model was also utilized to illustrate active targeting against CD44 and EGFR receptors in breast and colon cancer cell lines. Specific targeting of surface receptors improves the effectiveness of nanomedicines and makes cancer stem cells sensitive to paclitaxel chemotherapy.

In this example, we see some of the same multifunctionality that we reviewed in previous sections. This design for targeting stem cells involves micelles, which were

Table 3 Stem cell targeting nanodrugs for HER2-positive breast cancer

\begin{tabular}{|c|c|c|c|}
\hline Nanotechnology & Stem cell target & Therapy & References \\
\hline $\begin{array}{l}\text { Conjugation of hyaluronic acid and grafting the doublecor- } \\
\text { tin-like kinase } 1 \text { monoclonal antibody to the surface of } \\
\text { nanoparticles }\end{array}$ & CD44 receptors & None & Qiao et al. (2016) \\
\hline $\begin{array}{l}\text { Encapsulated polymeric nanoparticle surface modified } \\
\text { with chitosan }\end{array}$ & CD44 receptors & Doxorubicin & Rao et al. (2015) \\
\hline Fluorescent micelles & CD44 and EGRF & Paclitaxel & Gener et al. (2015) \\
\hline
\end{tabular}


functionalized for targeting, imaging and drug delivery. Here the CD44/EGFR targeting micelles were made fluorescent for imaging and detection, and loaded with the chemotherapy paclitaxel for stem cell killing. A summary of the stem cell nanotechnology designs can be found in Table 3 .

In addition to the importance of stem cell targeting for HER2 breast cancer, it is also vital to understand that this cancer can become resistant to chemotherapy, even when delivered via targeting. A co-delivery approach using more than one targeted therapy might overcome such resistance. Therefore, the following section specifically addresses this issue, covering the work being done to overcome resistance and cancer relapse using nanotechnology co-delivery strategies.

\section{Co-delivery approaches to addressing HER2-positive breast cancer}

Single-drug chemotherapy to treat breast cancer faces several limitations. These limitations include but are not limited to poor bioavailability of therapeutic drugs and multidrug resistance. Additionally, accumulation of a drug at the treatment site can be too low to be effective, making higher drug doses necessary and, thus, resulting in negative side effects. Furthermore, the potency of chemotherapies may be lacking, which can result in an inability to suppress cancer growth, especially in the heterogeneous distribution of cancer cells in tumors. To overcome these limitations, combination chemotherapy that utilizes multiple anticancer drugs has been developed, offering the potential to lower resistance and side effects (Zhang et al. 2016). Still, the challenge remains to achieve an antitumor effect with reduced toxicity. To address this issue, nanodrugs such as hydrogels, liposomes, nanocapsules, and other co-delivery designs have been reported. These co-delivery nanodrugs work to enhance the therapeutic efficacy of anticancer drugs by facilitating local accumulation of the drug and enhancing bioavailability (Zhang et al. 2016). Most significantly, these co-delivery nanodrugs provide an approach for incorporating two or more drugs that employ different mechanisms of action into a single vector. The co-delivery strategies reported in this section are specifically designed for the treatment of HER2-positive breast cancer. The nanotechnology designs for co-delivery in the section are co-delivery of rapamycin and imaging probes, co-delivery of doxorubicin and paclitaxel, and a liposome delivery of chemotherapy and immunosuppressant.

\section{Co-delivery of rapamycin and imaging probes in HER2-positive breast cancer}

One nano-based approach to targeting the HER2 receptor and employing co-delivery involves a lipid-based nanoparticle conjugated to trastuzumab (Tmab). This formulation uses rapamycin as a payload for its anticancer affect. This particular "nanotheranostic" formulation incorporates quantum dots as well, to serve as an imaging probe. The lipid encapsulates both the rapamycin and the quantum dots, and the surface of the lipid is conjugated to Tmab to target the HER2 receptor. This Tmab-functionalized lipid nanoparticle was designed to offer more efficient uptake and better therapy outcomes via HER2 receptor targeting. Upon cellular uptake via endocytosis, the contents of the lipid are released into the cancer cell, and the rapamycin works by down regulating the mTOR signaling pathway (Priyambada Parhi 2015). In this example of co-delivery, we see more co-function or multifunction. The therapy within this design is the rapamycin, which is effective at downregulating mTOR and stopping cancer growth. This design delivers 


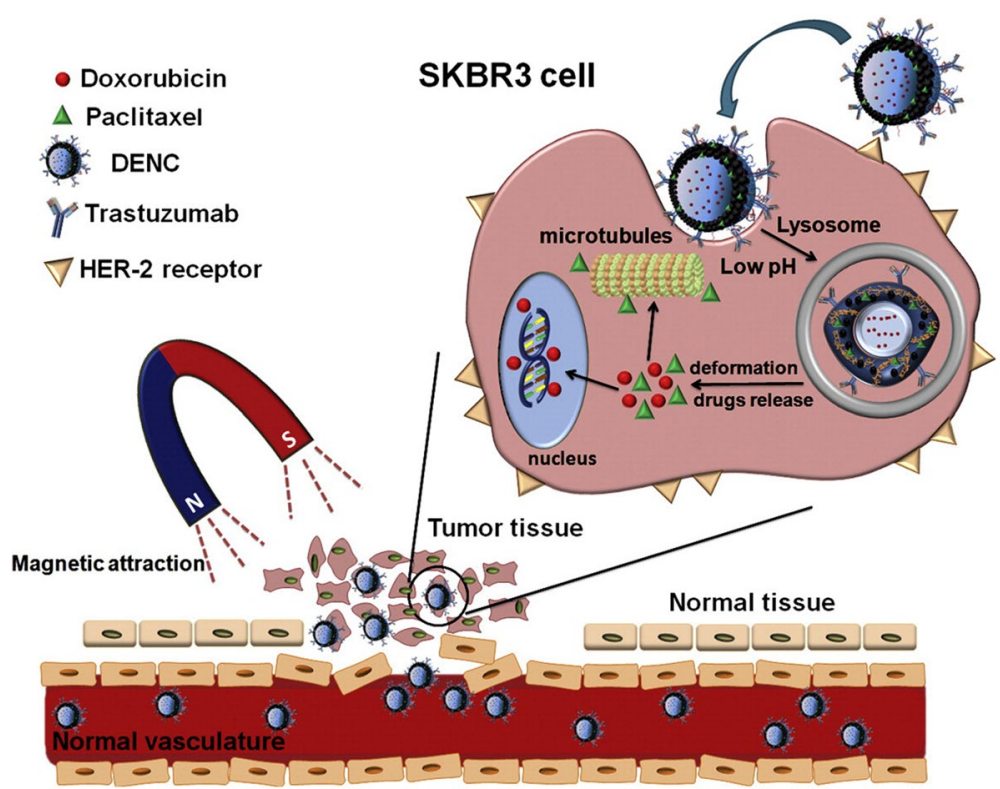

Fig. 8 Trastuzumab was conjugated to $\mathrm{pH}$-sensitive double-emulsion nanocapsules (DENCs). This nanocapsule is stabilized by a single-component poly(vinyl alcohol) with magnetic nanoparticles. The design can be used to encapsulate both hydrophilic Dox and hydrophobic PTX at the same time for co-delivery. This nanocapsule is conjugated to Tmab to target HER2-positive breast tumor tissues and is guided to the tumor site via magnetic force, where it can then deliver a dual anticancer drug payload (Reprinted from Enhancement of cancer therapy efficacy by trastuzumab-conjugated and $\mathrm{pH}$-sensitive nanocapsules with the simultaneous encapsulation of hydrophilic and hydrophobic compounds, Chih-Sheng Chiang, Shang-Hsiu Hu, Bang-Jie Liao, Yuan-Ching Chang, San-Yuan Chen, Copyright (2014), with permission from Elsevier)

the rapamycin while simultaneously delivering the quantum dots for imaging. The whole system is able to target the cancer via targeting the HER2 receptor. Next, we look at an example of two different chemotherapies being delivered simultaneously.

\section{Targeting nanocapsule delivers doxorubicin and paclitaxel}

In 2014, Chiang et al. conjugated Tmab to $\mathrm{pH}$-sensitive double-emulsion nanocapsules (DENCs). This nanocapsule was stabilized by a single-component poly (vinyl alcohol) with magnetic nanoparticles. The design can encapsulate hydrophilic doxorubicin (Dox) and hydrophobic paclitaxel (PTX) at the same time for the purpose of co-delivery. The nanocapsule was conjugated to Tmab to target HER2-positive breast tumor tissues and could be guided to the tumor site via magnetic force, where it could then deliver a dual anticancer drug payload. The targeting mechanism showed enhanced cellular uptake, as demonstrated by incubating SKBR3 cells with DENCs and analyzing cellular uptake with flow cytometry and confocal microscopy. The nanocapsule is also a pH-responsive drug carrier, relying on the drugs' interaction with the lysosomes of the tumor cells to control release (Fig. 8). In vivo studies utilized mice with HER2-positive xenograft, created via injections of SKBR3 and Matrigel. The nanocapsules were then administered via tail vein injection and guided to the tumor location using magnets. The results indicated that, by targeting with Tmab and using $\mathrm{pH}$-controlled drug release, the T-PTX-DENC was able to reduce tumor cell viability to $25-30 \%$. When both PTX and DOX were loaded on the 


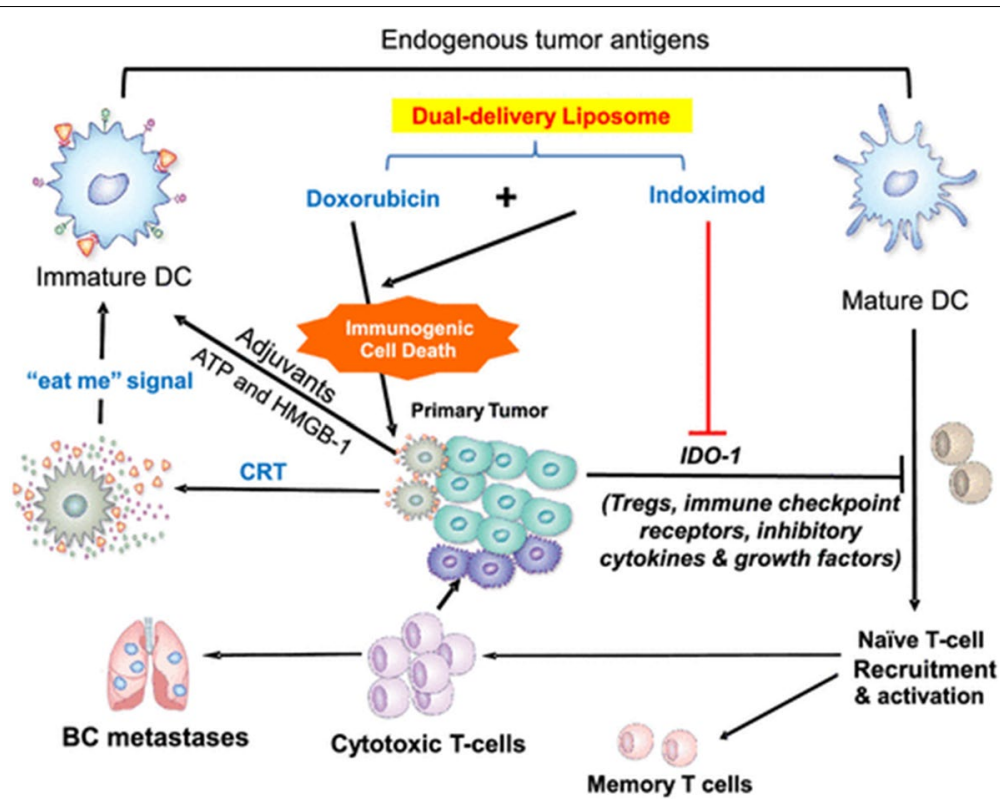

Fig. 9 Schematic to explain BC immunotherapy by combined delivery of an immunogenic cell death stimulus plus an inhibitor of the IDO-1 pathway. DOX delivery to the tumor site provides an effective stimulus for ICD, which is characterized by calreticulin (CRT) expression (an "eat-me" signal for dendritic cell uptake) on the cancer cell surface. Subsequent release of adjuvant stimuli, HMGB-1 and ATP, by the dying cancer cells induces DC maturation and tumor antigen presentation to naive T-cells. Recruitment of CD8 ${ }^{+}$cytotoxic T-lymphocytes triggers a full-fledged immune response, provided that the tumor infiltrating lymphocytes can escape the immunosuppressive micromilieu at the BC tumor site. These immunosuppressive pathways include a contribution by FOXP-3+ regulatory T-cells, autoregulatory effects of immune checkpoint receptors (e.g., PD-1), and the metabolic effects of the overexpressed IDO-1 immune surveillance pathway. The small molecule inhibitor IND interferes in the IDO-1 pathway. The improved pharmacokinetics of drug delivery by the nanocarrier allows achievement of sufficiently high tumor drug levels to trigger an effective and sustained immune response for the reduction or elimination of the primary $\mathrm{BC}$ tumor and its metastases (Reprinted with permission from (Lu et al. 2018). Copyright 2018, American Chemical Society. Further permissions related to the material excerpted should be directed to the ACS)

nanosystem, cell viability decreased even further to around 10\%, indicating that the anticancer drug combination had a powerful synergistic effect.

Drug resistance can be an issue with any cancer type. This example provides a good technology for better treatment outcomes by co-delivering two chemotherapies simultaneously in a targeting manner. This last example in this section involves the co-delivery of a chemotherapy and an immunosuppressant.

\section{Liposomal delivery of chemotherapy and immunosuppressant}

Finally, a chemo-immunotherapy approach for breast cancer was demonstrated by $\mathrm{Lu}$ et al. (2018). In this work, a dual-drug delivery liposomal carrier was used to introduce an immunogenic cell death signal and interfere in the regionally overexpressed indolamine 2,3-dioxygenase (IDO-1) pathway that prevents T-cell priming. This liposome delivers Dox to provide an immunogenic cell death (ICD) stimulus and an indoximod (IND) prodrug that interferes in the metabolic immunosuppressive effects of the IDO-1 pathway of the tumor (Fig. 9). The dual-delivery carrier system improved the anti-breast cancer immune response at the primary and metastatic sites better than the Dox-only 
Table 4 Nanotechnology designs of co-delivery targeting drugs

\begin{tabular}{|c|c|c|c|}
\hline Delivery system & HER2 targeting & Co-delivery & References \\
\hline Lipid-based nanoparticle & Trastuzumab & Rapamycin and quantum dots & $\begin{array}{l}\text { Priyambada Parhi } \\
\text { (2015) }\end{array}$ \\
\hline $\begin{array}{l}\text { pH-sensitive double-emul- } \\
\text { sion nanocapsule }\end{array}$ & Trastuzumab & $\begin{array}{l}\text { Magnetic nanoparticles/doxoru- } \\
\text { bicin and paclitaxel }\end{array}$ & Chiang et al. (2014) \\
\hline Liposomal carrier & $\begin{array}{l}\text { Targets immune } \\
\text { response to breast } \\
\text { cancer }\end{array}$ & Doxorubicin and indoximod & Lu et al. (2018) \\
\hline
\end{tabular}

liposome. Intravenous injections of this DOX/IND-liposome system enhanced the pharmacokinetics and uptake of both drugs at the tumor site in a breast cancer model (4T1 orthotopic BC model in syngeneic mice). It was further shown that the response was augmented by adding anti-PD-1 monoclonal antibody to eliminate lung metastases. From an immunological perspective, this study clearly demonstrates the benefits of codelivery over free drugs or single-drug nanoparticles alone.

This is a good example of how targeting HER2-positive breast cancer and delivering multiple therapies can improve treatment outcomes. The co-delivery designs of this section are listed in Table 4.

This section described a number of the co-delivery systems developed to treat most complex cancer types, e.g., HER2-positive breast cancer. A multi-purpose, multifunctional targeting nanodrug is ideal for HER2-positive breast cancer, as it is complex and we need to treat it using complex approaches. In many cases, it may be necessary to attack cancer with multiple therapies to overcome drug resistance, and co-delivery strategies make this possible while maintaining the function of tumor targeting.

\section{Concluding remarks and future directions}

In this review, we have highlighted nanotechnology approaches to combating HER2positive breast cancer. The sections of this review include cellular uptake of nanomaterials in HER2-positive breast cancer models, screening and detecting HER2-positive breast cancer using nanotechnology, targeting and drug delivery, stem cell research, and co-delivery strategies and designs to enhance treatment outcomes.

The section on cellular uptake shows us how dynamic this process can be. We looked at the different models in this section and saw that any slight variation such as size, shape, surface chemistry and cell type are factors that influence the cellular uptake behavior. In addition to providing information about the cellular uptake process specific to the models in this review, this section also provides the researcher with the different techniques and approaches available for studying the cellular uptake process in different breast cancer/nanotechnology models. We can never assume this process works in the same way as another model and if anything is different, e.g., particle type, size, concentration, target cell or tissue then this process needs to be investigated. While the cellular uptake information provided by the authors of the works in this review is very useful to aid our understanding, more work needs to be done in this area to help us design better and more effective nanodrugs to combat HER2-positive breast cancer. 
The section on screening and detecting Her2-positive breast cancer provides us with examples of great research done in this area. It is crucial in the fight against this disease to be able to screen, detect and catch the cancer early to improve prognoses and treatment success. Not only can we take from this section the contribution made by the original investigators of the works in the review, but the ideas and possibilities that can be taken from this. Here we see three different nanotechnology designs for screening and detecting HER2-positive breast cancer that are very different from one another. Iron oxide nanoparticles, which are easily conjugated, with fluorescent labels for imaging were shown to be useful for detecting HER2 in blood samples. Dendrimers were shown to be a targeting alternative to trastuzumab and quantum dots were shown to be very multifunctional, which is ideal for any nanotechnology design for cancer treatment. This section provides good insight into the work being done in this area as it specifically relates to HER2-positive breast cancer and gives us ideas to push the designs and technology even further to come up with more effective designs that serve not only to screen and detect but more functionality such as drug delivery.

In the section on targeting we see different approaches and designs for targeting the HER2-positive breast cancer cells and tumors. If fact, this targeting strategy is seen in most of the designs throughout this review. The fact that this cancer overexpresses the HER2 receptor makes this cancer vulnerable to the targeting strategies making many different designs for targeting possible. In this section we see the use of trastuzumab, Anti-HER2, peptides and aptamers as well as minidrugs to target this cancer. In addition to the targeting mechanism we see many examples of the differences in particle type from metals like gold to non-metals such as nanobubbles. This section also highlights the ultimate goal of this technology, which is cell killing and combating the cancer itself by delivering therapies. The targeting is important to signal out the cancer and avoid the healthy surrounding tissue, but it is incomplete without a payload of some kind or without therapeutic capability. This section shows us great examples of "targeting nanodrugs", which are specific to HER2-positive breast cancer.

When it comes to stem cells it is important to understand that addressing cancer stem cells is crucial and if the cancer stem cells are not addressed then any effort of using nanodrugs may not be enough due to cancer spreading and cancer recurrence. In the previous sections we talk about cellular uptake, screening and detecting and targeting the cancer cells and its helpful to really see that all of these areas of research are pieces that should work together to reach the goal of treating this disease. For example, we need nanodrugs that have all these functions combined. We need a nanodrug that can target the HER2-positive cancer, with the ability to image and detect, while also providing a therapeutic benefit. With this design we must be able to understand how it works, which makes the understanding of cellular uptake, localization, and mechanisms of action so crucial. The issue with stem cells is a separate issue that must be dealt with or addressed separately from the cancer cells and tumors. In other words, the designs we see in this review are specific to tumors or cells or they are specific to stem cells, but no technology reviewed here has the capability to address both. Stem cells do not have HER2 receptors and targeting stem cells for cancer is different than the way we target the normal cancer cells and tumors, but cancer stem cells are still an issue with HER2-positive breast cancer, and they must be addressed. 
Co-delivery may very well be the solution. The co-delivery section really highlights some of the most exciting nanodrug designs. In this section we see how either multiple chemotherapies can be delivered simultaneously, or how different types of drugs and even imaging probes can be delivered. Cancer is dynamic in that treatments do not always work, and it becomes relapsing and resistant. The co-delivery research opens up lots of possibilities to combat these issues by engineering nano-constructs that can be tailored to patients and designed to release multiple therapies at once to target different issues with this disease.

Moving forward, we need more multifunctional nanodrug designs that can address the complexity of this problem. Furthermore, we need to be certain of the ideal particle type for this type of cancer while considering patient differences, and in every design, the mechanism of action must be understood. The toxicity issues and the long-term effects on humans and the environment need to be defined. Finally, most current work is done in vitro and in animals. Taking these nano-designs from the lab to the clinic is the next most important step to test their efficacy and safety in humans.

\section{Acknowledgements}

We are grateful to Emily Davis for the review and assistance with the technical editing of this manuscript.

\section{Authors' contributions}

BEW conceived of the presented review and is the first author and author of correspondence. MKW assisted with the overall review of the literature. HA assisted with the overall review of the literature and collection of published works to be reviewed. IM assisted in supervising the format and content of the manuscript. ZN assisted with figures, direction for obtaining figure permissions and with formatting. ASB supervised this project, helped in writing the manuscript and the peer review revisions. NA supervised this project and assisted in the peer review response and the writing of the manuscript. All authors read and approved the final manuscript.

\section{Funding}

We acknowledge support from the Arkansas EPSCOR Program, ASSET III.

\section{Availability of data and materials}

Data sharing not applicable to this article as no datasets were generated or analyzed during the current study.

\section{Ethics approval and consent to participate}

Not applicable.

\section{Consent for publication}

Figures were reproduced with permissions from the authors and or publishers.

\section{Competing interests}

The authors declare that they have no competing interests.

\section{Author details}

${ }^{1}$ Department of Biology, College of Arts, Letters and Sciences, University of Arkansas at Little Rock, Little Rock, AR, USA.

${ }^{2}$ Center for Integrative Nanotechnology Sciences, University of Arkansas at Little Rock, Little Rock, AR, USA. ${ }^{3}$ Medical

Oncology, University of Arkansas for Medical Sciences, Little Rock, AR, USA.

Received: 19 June 2020 Accepted: 3 October 2020

Published online: 17 October 2020

\section{References}

American Cancer Society. Cancer facts and figures 2018. 2020. https://www.cancer.org/content/dam/cancer-org/resea rch/cancer-facts-and-statistics/annual-cancer-facts-and-figures/2018/cancer-facts-and-figures-2018.pdf.

Avazzadeh R, Vasheghani-farahani E, Soleimani M, Amanpour S, Sadeghi M. Synthesis and application of magnetite dextran-spermine nanoparticles in breast cancer hyperthermia. Prog Biomater. 2017;6(3):75-84. https://doi. org/10.1007/s40204-017-0068-8.

BREASTCANCER.ORG (2020) U.S. breast cancer statistics. https://www.breastcancer.org/symptoms/understand_bc/stati stics.

Cao X, Yu H, Chen C, Wei J, Wang P. Expression and characterization of recombinant humanized anti-HER2 single-chain antibody in Pichia pastoris for targeted cancer therapy. Biotechnol Lett. 2015;37(7):1347-54. https://doi.org/10.1007/ s10529-015-1804-6.

Chan C, Cai Z. 2020. https://link.springer.com/article/10.1007/s11095-013-1044-1. 
Chemocare.com. Ado-Trastuzumab Emtansin. 2019. https://chemocare.com/chemotherapy/drug-info/ado-trastuzuma b-emtansine.aspx.

Chiang C-S, Hu S-H, Liao B-J, Chang Y-C, Chen S-Y. Enhancement of cancer therapy efficacy by trastuzumab-conjugated and $\mathrm{pH}$-sensitive nanocapsules with the simultaneous encapsulation of hydrophilic and hydrophobic compounds. Nanomed Nanotechnol Biol Med. 2014;10(1):99-107. https://doi.org/10.1016/j.nano.2013.07.009.

Cho EC, Liu Y, Xia Y. A simple spectroscopic method for differentiating cellular uptakes of gold nanospheres and nanorods from their mixtures. Angew Chem Int Ed. 2010;49(11):1976-80. https://doi.org/10.1002/anie.200906584.

Choi WI, Lee JH, Kim J-Y, Heo SU, Jeong YY, Kim YH, Tae G. Targeted antitumor efficacy and imaging via multifunctional nano-carrier conjugated with anti-HER2 trastuzumab. Nanomed Nanotechnol Biol Med. 2015;11(2):359-68. https:// doi.org/10.1016/j.nano.2014.09.009.

Cruz E, Kayser V. Synthesis and enhanced cellular uptake in vitro of anti-HER2 multifunctional gold nanoparticles. Cancers. 2019. https://doi.org/10.3390/cancers11060870.

Dawidczyk CM, Russell LM, Searson PC. Nanomedicines for cancer therapy: state-of-the-art and limitations to pre-clinical studies that hinder future developments. Front Chem. 2014. https://doi.org/10.3389/fchem.2014.00069.

Day ES, Bickford LR, Slater JH, Riggall NS, Drezek RA, West JL. Antibody-conjugated gold-gold sulfide nanoparticles as multifunctional agents for imaging and therapy of breast cancer. Int J Nanomed. 2010;5:445-54.

Ding H, Gangalum PR, Galstyan A, Fox I, Patil R, Hubbard P, et al. HER2-positive breast cancer targeting and treatment by a peptide-conjugated mini nanodrug. Nanomed Nanotechnol Biol Med. 2017;13(2):631-9. https://doi.org/10.1016/j. nano.2016.07.013.

Dreaden EC. The golden age: gold nanoparticles for biomedicine. Chem Soc Rev. 2012;(7):2521-3012.

Emami M, Shamsipur M, Saber R, Irajirad R. An electrochemical immunosensor for detection of a breast cancer biomarker based on antiHER2—iron oxide nanoparticle bioconjugates. Analyst. 2014;139(11):2858-66. https://doi.org/10.1039/ C4AN00183D.

Fam-Trastuzumab Deruxtecan. Drugs.com. 2020. https://www.drugs.com/ppa/fam-trastuzumab-deruxtecan.html.

Gener P, Gouveia LP, Sabat GR, de Sousa Rafael DF, Fort NB, Arranja A, et al. Fluorescent CSC models evidence that targeted nanomedicines improve treatment sensitivity of breast and colon cancer stem cells. Nanomed Nanotechnol Biol Med. 2015;11(8):1883-92. https://doi.org/10.1016/j.nano.2015.07.009.

Ghosh P, Han G, De M, Kim CK, Rotello VM. Gold nanoparticles in delivery applications. Adv Drug Deliv Rev. 2008;1307-15.

Hicks DG. Her2+ breast cancer: review of biologic relevance and optimal use of diagnostic tools. Am J Clin Pathol. 2008;129:263-73.

Jiang Q, Hao S, Xiao X, Yao J, Ou B, Zhao Z, et al. Production and characterization of a novel long-acting Herceptin-targeted nanobubble contrast agent specific for Her-2-positive breast cancers. Breast Cancer. 2016;23(3):445-55. https ://doi.org/10.1007/s12282-014-0581-8.

Kang X, Guo X, An W, Niu X, Li S, Liu Z, et al. Photothermal therapeutic application of gold nanorods-porphyrin-trastuzumab complexes in HER2-positive breast cancer. Sci Rep. 2017;7:42069. https://doi.org/10.1038/srep42069.

Kulhari H, Pooja D, Shrivastava S, Kuncha M, Naidu VGM, Bansal V, et al. Trastuzumab-grafted PAMAM dendrimers for the selective delivery of anticancer drugs to HER2-positive breast cancer. Sci Rep. 2016;6:23179. https://doi.org/10.1038/ srep23179.

Lee H, Dam DHM, Ha JW, Yue J, Odom TW. Enhanced human epidermal growth factor receptor 2 degradation in breast cancer cells by lysosome-targeting gold nanoconstructs. ACS Nano. 2015;9(10):9859-67. https://doi.org/10.1021/ acsnano.5b05138.

Lu J, Liu X, Liao Y-P, Wang X, Ahmed A, Jiang W, et al. Breast cancer chemo-immunotherapy through liposomal delivery of an immunogenic cell death stimulus plus interference in the IDO-1 pathway. ACS Nano. 2018;12(11):11041-61. https://doi.org/10.1021/acsnano.8b05189.

Martínez-Jothar LM-J. Selective cytotoxicity to HER2 positive breast cancer cells by saporin-loaded nanobody-targeted polymeric nanoparticles in combination with photochemical internalization. Mol Pharm. 2020;1633-47.

Miyano T. ACS Publications. 2020. https://pubs.acs.org/doi/abs/10.1021/mp100105c.

Mu Q, Kievit FM, Kant RJ, Lin G, Jeon M, Zhang M. Anti-HER2/neu peptide-conjugated iron oxide nanoparticles for targeted delivery of paclitaxel to breast cancer cells. Nanoscale. 2015;7(43):18010-4. https://doi.org/10.1039/C5NRO 4867B.

Navas-Moreno M, Mehrpouyan M, Chernenko T, Candas D, Fan M, Li JJ, et al. Nanoparticles for live cell microscopy: a surface-enhanced Raman scattering perspective. Sci Rep. 2017;7:1-10. https://doi.org/10.1038/s41598-017-04066-0.

NDong C, Tate JA, Kett WC, Batra J, Demidenko E, Lewis LD, et al. Tumor cell targeting by iron oxide nanoparticles is dominated by different factors in vitro versus in vivo. PLOS ONE. 2015;10(2):e0115636. https://doi.org/10.1371/journ al.pone.0115636.

Panariti A, Miserocchi G, Rivolta I. The effect of nanoparticle uptake on cellular behavior: disrupting or enabling functions? Nanotechnol Sci Appl. 2012;5:87-100. https://doi.org/10.2147/NSA.S25515.

Patiño T, Soriano J, Barrios L, Ibáñez E, Nogués C. Surface modification of microparticles causes differential uptake responses in normal and tumoral human breast epithelial cells. Sci Rep. 2015;5:11371. https://doi.org/10.1038/srep1 1371.

PERJETA and HER2 + breast cancer. 2019. https://www.perjeta.com/hcp/breast-cancer/about-perjeta.html?c=per-1645c 217be4\&gclid=EAlalQobChMIINHu2oG_5QIVCtbACh3SMghiEAAYAiAAEgJNWvD_BwE\&gclsrc=aw.ds.

Priyambada Parhi SK. Trastuzumab guided nanotheranostics: a lipid based multifunctional nanoformulation for targeted drug delivery and imaging in breast cancer therapy. J Colloid Interface Sci. 2015;198-211. 
Qiao S, Zhao Y, Geng S, Li Y, Hou X, Liu Y, et al. A novel double-targeted nondrug delivery system for targeting cancer stem cells. Int J Nanomed. 2016;11:6667-78 (27994463).

Rameshwer Shukla TP-L. 2020. https://pubs.acs.org/doi/abs/10.1021/bc050348p

Rao W, Wang H, Han J, Zhao S, Dumbleton J, Agarwal P, et al. Chitosan-decorated doxorubicin-encapsulated nanoparticle targets and eliminates tumor reinitiating cancer stem-like cells. ACS Nano. 2015;9(6):5725-40. https://doi. org/10.1021/nn506928p.

Rizvi SB, Rouhi S, Taniguchi S, Yang SY, Green M, Keshtgar M, Seifalian AM. Near-infrared quantum dots for HER2 localization and imaging of cancer cells. Int J Nanomed. 2014;9:1323-37. https://doi.org/10.2147/JJN.S51535.

Shakil MS, Hasan MA, Sarker SR. Iron oxide nanoparticles for breast cancer theranostics. Curr Drug Metab. 2019;446-56.

Sperling PRRA, et al. Biological applications of gold nanoparticles. Chem Soc Rev. 2008;(9):1745-2140.

Sutapa Barua J-WY. Particle shape enhances specificity of antibody-displaying nanoparticles. 2020

Targeted Therapy. National Breast Cancer Foundation, Inc. 2019. https://www.nationalbreastcancer.org/breast-cance r-targeted-therapy.

Targeted Therapy for Breast Cancer. American Cancer Society. 2019. https://www.cancer.org/cancer/breast-cancer/treat ment/targeted-therapy-for-breast-cancer.html.

Truffi M, Colombo M, Sorrentino L, Pandolfi L, Mazzucchelli S, et al. Multivalent exposure of trastuzumab on iron oxide nanoparticles improves antitumor potential and reduces resistance in HER2-positive breast cancer cells. Sci Rep. 2018:8:1-11. https://doi.org/10.1038/s41598-018-24968-x.

Tucatinib. PubChem. 2020. https://pubchem.ncbi.nlm.nih.gov/compound/Tucatinib.

U.S. National Library of Medicine. Neratinib. 2019. https://pubchem.ncbi.n/m.nih.gov/compound/Neratinib.

Wang Z, Wang W, Bu X, Wei Z, Geng L, Wu Y, et al. Microarray based screening of peptide nano probes for HER2 positive tumor. Anal Chem. 2015;87(16):8367-72. https://doi.org/10.1021/acs.analchem.5b01588.

Zhang Y, Yang C, Wang W, Liu J, Liu Q, Huang F, et al. Co-delivery of doxorubicin and curcumin by pH-sensitive prodrug nanoparticle for combination therapy of cancer. Sci Rep. 2016. https://doi.org/10.1038/srep21225.

\section{Publisher's Note}

Springer Nature remains neutral with regard to jurisdictional claims in published maps and institutional affiliations.

- fast, convenient online submission

- thorough peer review by experienced researchers in your field

- rapid publication on acceptance

- support for research data, including large and complex data types

- gold Open Access which fosters wider collaboration and increased citations

- maximum visibility for your research: over 100M website views per year

At BMC, research is always in progress.

Learn more biomedcentral.com/submissions 